\title{
POTENCIALIDADES FUNCIONAIS E NUTRACÊUTICAS DAS PROTEÍNAS DO LEITE BOVINO
}

\author{
Functional and nutraceutical potential of proteins from bovine milk \\ Diego Prado de Vargas', José Laerte Nörnberg², Luciano Antônio Ritt ${ }^{3}$, Rudolf Brand Sheibler ${ }^{4}$, Fábio Antu- \\ nes Rizzo ${ }^{5}$, Marceli Pazini Milani ${ }^{6}$ \\ 'Universidade Federal de Santa Maria (UFSM)-Aluno de Doutorado do Programa de Pós-Graduação em Ciência e Tecnologia dos Alimen- \\ tos \\ 2UFSM - Profo. Associado do Departamento de Tecnologia e Ciência dos Alimentos \\ 3UFSM - Aluno do curso de Zootecnia \\ ${ }^{4}$ Universidade Federal de Pelotas (UFPEI) - Aluno de Doutorado do Programa de Pós-Graduação em Zootecnia \\ ${ }^{5}$ UFPEI - Aluno de Doutorado do Programa de Pós-Graduação em Zootecnia \\ ¿UFSM - Aluna de Doutorado Programa de Pós-Graduação em Ciência e Tecnologia dos Alimentos
}

\begin{abstract}
Resumo
Objetivou-se com esta revisão, caracterizar os efeitos dos peptídeos bioativos (PBA) derivados do leite bovino nos principais sistemas corpóreos, incluindo os sistemas cardiovascular, digestivo, imunológico e nervoso. Com essa finalidade, estudaram-se as principais características, formas de obtenção, composição e mecanismos de ação destes fragmentos proteicos codificados na região primária das proteínas do leite, como, os peptídeos inibidores da enzima conversora da angiotensina (ECA), antitrombóticos, opióides, imunomoduladores, antimicrobianos e, os caseinomacropeptídeos (CMP) e caseínofosfopeptídeos (CFP). Assim, com o aumento das exigências por parte dos consumidores e, consequentemente, pela indústria alimentícia, quanto à qualidade nutricional dos alimentos e, o recente avanço científico e tecnológico em relação aos efeitos e produção dos PBA, têm-se excelentes perspectivas futuras para este emergente mercado de produtos lácteos funcionais. Palavras-chave: alimentos funcionais, leite, peptídeos bioativos, saúde.
\end{abstract}

\begin{abstract}
This review aims to characterize the effects of bioactive peptides (BAP) derived from bovine milk in the major body systems, including the cardiovascular, digestive, immune and nervous systems. To this end, we studied the main characteristics, ways of obtaining, composition and mechanisms of action of these protein fragments encoded in the primary region of milk proteins, as the peptide inhibitors of angiotensin-converting enzyme (ACE) inhibitors, antithrombotics, opioids, immunomodulators, antimicrobials, and the caseinmacropeptides (CMP) and caseinophosphopeptides (CPP). Thus, with increasing demands by consumers and, consequently, the food industry, as the nutritional quality of foods and recent scientific and technological advances for the effects of PBA and production, have become excellent future prospects for this emerging market for functional dairy products.
\end{abstract}

Keywords: bioactive peptides, functional foods, health, milk 


\section{INTRODUÇÃO}

As proteínas representam entre 3 e 4\% dos sólidos encontrados no leite bovino, e são subdivididas basicamente entre proteínas do soro (soroproteínas) e caseína (OLIVEIRA; TIMM, 2007), representando respectivamente, $20 \%$ e $80 \%$, do total das proteínas lácteas (HAQUE; CHAND, 2006).

A caseína bovina pode ser classificada em quatro tipos de proteínas com diferentes propriedades: as1-, $\alpha$ s2-, $\beta$ - e к-caseína, perfazendo respectivamente, $38 \%, 10 \%, 34 \%$ e $15 \%$ da caseína total (FOX et al., 2000).

Da mesma forma, a fração de proteína do soro (soroproteínas) do leite bovino, também contém quatro principais proteínas: $\beta$-lactoglobulina $(50 \%)$, $\alpha$-lactalbumina (20\%), soroalbumina (10\%) e imunoglobulinas (10\%), como a IgG1 (principalmente), IgG2, IgA e IgM (FOX et al., 2000).

Além de exercerem diversas funções básicas de nutrição (fonte de aminoácidos para síntese proteica e de energia) e tecnológicas (propriedades funcionais e sensoriais), recentemente, tem-se reconhecido que as proteínas do leite possuem sequências de peptídeos que exercem influência em funções biológicas, como, secreção de hormônios, defesa imune, absorção de nutrientes, transmissão da informação neurológica e crescimento microbiano (CLARE; SWAISGOOD, 2000; CLARE et. al., 2003; FITZGERALD; MEISEL, 2003) e, por este motivo, estes fragmentos proteicos específicos são denominados peptídeos bioativos (PBA) ou biofuncionais.

Os PBA contêm de 2 a 20 resíduos de aminoácidos por molécula e, normalmente são inativos dentro de sua sequência molecular (KORHONEN, 2009), entretanto, podem ser liberados in vivo por atividade proteolítica no estômago e/ou nos intestinos, produzidos in vitro a partir de proteínas do leite, com a utilização de algumas proteinases provenientes de microrganismos ou plantas, ou ainda, produzidos através de síntese química (PHELAN et. al., 2009).

Devido ao grande número de PBA codificados em sua região primária, as proteínas do leite são consideradas, no momento, as principais fontes conhecidas de uma variedade de peptídeos funcionais.

Dessa forma, estudos que descrevam os progressos tecnológicos e científicos sobre as funcionalidades dos PBA do leite bovino e seus derivados, auxiliam no desenvolvimento deste emergente mercado de produtos lácteos funcio- nais e, no consequente fortalecimento da cadeia láctea nacional.

Diante do exposto, objetivou-se com esta revisão, caracterizar os efeitos dos PBA derivados do leite bovino nos principais sistemas corpóreos, incluindo, os sistemas cardiovascular, digestivo, imune e nervoso.

\section{EFEITOS NO SISTEMA CARDIOVASCU. LAR}

Peptídeos funcionais presentes no leite ou produtos lácteos, têm demonstrado exercer efeitos no sistema cardiovascular, principalmente através de suas ações anti-hipertensivas, antitrombóticas e hipocolesterolêmicas.

A regulação da pressão sanguínea é parcialmente dependente do sistema renina-angiotensina-aldosterona. A renina atua sobre a angiotensina, liberando a angiotensina I, esta, por sua vez, converte-se em angiotensina II, um potente vasoconstritor, pela ação da enzima conversora de angiotensina (ECA). A angiotensina II inativa a bradicinina, um vasodilatador, aumentando a produção de aldosterona e, consequentemente, resultando em diminuição da excreção renal e elevação da retenção de líquidos pelo organismo (SILVA; MALCATA, 2005).

Peptídeos inibidores da ECA estão entre os compostos bioativos mais estudados e, embora diversas proteínas alimentares possam agir como seus precursores, as proteínas lácteas são as mais importantes fontes destes peptídeos, como fica evidenciado na Tabela 1.

Neste contexto, estes peptídeos são capazes de proporcionar efeito anti-hipertensivo por inibição da ECA, além de influenciar diferentes sistemas regulatórios envolvidos na modulação da pressão arterial, como o sistema cardiovascular, imune e nervoso (PRIPP et. al., 2006; LIGNITTO et al., 2010). Entretanto, é importante destacar que proteínas lácteas também podem exercer efeitos anti-hipertensivos por outros mecanismos, como através da inibição da liberação da endotelina-1 por células endoteliais, estimulação da atividade da bradicinina, aumento da produção de óxido nítrico derivado do endotélio e aumento da ação vasodilatadora de ligantes dos receptores opiáceos (KORHONEN; PIHLANTO, 2006).

Os peptídeos inibidores da ECA derivados da caseína ( $\alpha$ s1-caseína e $\beta$-caseína) são denominados casoquininas, enquanto os derivados das proteínas do soro ( $\alpha$-lactoalbumina e $\beta$-lactoglobulina) 
de lactoquininas (PIHLANTO et. al., 1998; PRIPP et al., 2006; LIGNITTO et al., 2010).

Ainda sobre a ação dos PBA sobre o sistema circulatório e cardiovascular, a partir da clivagem da k-caseína bovina é possível produzir peptídeos derivados, como as casoplatelinas (Tabela 1), que possuem atividade inibidora da agregação plaquetária, por competição da ligação do fibrinogênio aos sítios receptores específicos sobre as superfícies das plaquetas (MEISEL, 1998). Recentemente, foi reportado que os caseinoglicopeptídeos também são fontes de peptídeos com ação antitrombótica (SILVA; MALCATA, 2005).

Além disso, alguns ensaios evidenciaram efeito positivo das proteínas do soro na redução dos níveis de triglicerídeos e do colesterol sanguíneo e/ou hepático. Neste sentido, Nagaoka et. al. (1992), em pesquisa com ratos compararam os efeitos da proteína de soja com as do soro de leite e, verificaram que os níveis de lipídios totais e de colesterol foram significativamente diminuídos pelo efeito das proteínas de soro, sendo que este comportamento observado foi significativamente maior frente ao constatado para as proteínas de soja. Ainda sobre os efeitos benéficos das proteínas do soro sobre o sistema circulatório e cardiovascular, segundo Sgarbieri (2004), estas poderão exercer diversas ações, devido às suas propriedades redutoras (cisteína e estímulo à síntese de glutationa) e sequestradoras de radicais livres (glutationa, lactoferrina, lactoperoxidase), que por sua vez atuam na inibição da lipoxidação das lipoproteínas e artérias.

\section{EFEITOS NO SISTEMA NERVOSO}

O leite e seus derivados são fontes dietéticas de peptídeos opioides (Tabela 1), os quais estão presentes em estruturas primárias das diversas proteínas do leite. Alguns destes peptídeos podem desempenhar funções regulatórias no sistema nervoso e digestivo, podendo exercer, quando ligados aos seus receptores opioides específicos (receptores $\mu, \delta$ e $\kappa$ ), atividades agonistas (principalmente fragmentos de $\alpha$ - e $\beta$-caseína) e antagonistas (principalmente fragmentos de $\mathrm{k}$-caseína) relacionadas à modulação destes sistemas fisiológicos (CLARE; SWAISGOOD, 2000).

O sistema opioide endógeno é formado por um conjunto de receptores e peptídeos ligantes endógenos que estão distribuídos no sistema nervoso central (SNC) e tecidos periféricos como o sistema imune, cardiovascular, endócrino e digestório e, por este motivo, é considerado crucial na homeostase corporal, regulando diversas respostas fisiológicas do organismo (BODNAR, 2009; TRIGO et. al., 2010).

Os peptídeos agonistas opioides são dotados de ação farmacológica semelhante aos compostos opioides e, já foram isolados na estrutura primária das frações $\beta$-caseína ( $\beta$-casomorfina) e da as1-caseína ( $\alpha$-casomorfina), bem como, na $\alpha$-lactalbumina, $\beta$-lactoglobulina e soralbumina presentes no soro do leite bovino (TIDONA et. al., 2008).

A característica estrutural comum destes fragmentos proteicos (exceto os derivados da as1caseína) consiste na presença de um resíduo de tirosina (Y) na sua porção N-terminal, conjuntamente com outro resíduo aromático na terceira ou quarta posição, tais como fenilanina $(F)$ ou tirosina (Y). Esta propriedade estrutural é um importante fator para a afinidade destes peptídeos ao sítio de ligação dos receptores opióides, além disso, o potencial negativo gerado pela hidroxila presente no grupo fenólico da tirosina parece ser essencial para estes, exercerem suas atividades (SILVA; MALCATA, 2005).

A morficetina, pertence ao grupo da $\beta$-casomorfina e, é considerado o peptídeo com maior potencial opióide já relatado na literatura, apresentando a seguinte sequência N-terminal: Y-P-F-P (SCHANBACHER et. al., 1998; SHAH, 2000).

Entretanto, quanto à ação de peptídeos opioides no sistema nervoso, é importante ressaltar que a penetração destes pela barreira hemato-encefálica em adultos é restrita, porém em determinadas condições, há evidências que alguns oligopeptídeos podem ultrapassá-la (CLARE; SWAISGOOD, 2000). Neste sentido, os peptídeos opioides podem exercer ação farmacológica na indução da apneia e respiração irregular, modulação do padrão do sono, estimulação da produção de insulina e somatostatina, indução de analgesia e, alteração do comportamento social (HARTMAN; MEISEL, 2007; SHAHIDI; ZHONG, 2008; SILVA; MALCATA, 2005). Da mesma maneira, Sturner e Chang (1988), devido ao transporte passivo das $\beta$-casomorfinas através das membranas da mucosa intestinal de recém-nascidos, evidenciaram que estes peptídeos, podem ocasionar respostas fisiológicas, tais como, efeitos analgésicos no sistema nervoso, resultando em calmaria e sonolência em lactentes. Em contraste, em adultos, devido à resistência das $\beta$-casomorfinas às enzimas do trato gastrointestinal, evidencia-se que suas influências 
fisiológicas estão limitadas a este local, com efeitos importantes sobre o tempo de trânsito intestinal, absorção de aminoácidos e estimulação da absorção de água e eletrólitos (SHAHIDI; ZHONG, 2008; HARTMANN; MEISEL, 2007; SILVA; MALCATA, 2005). Neste sentido, as $\beta$-casomorfinas podem reduzir a secreção gástrica e intestinal e, por este motivo, existe um grande interesse por seu possível benefício no tratamento de diarreias. Além disso, estes peptídeos podem ter um efeito local, sem a necessidade de absorção sistêmica, reduzindo o reflexo peristáltico através do decréscimo da resposta reflexa (ALLESCHER et al., 2000). Assim, isto evidencia um possível efeito terapêutico destes dos peptídeos opioides frente ao tratamento de desordens gástricas.

Por outro lado, a hidrólise das proteínas lácteas podem formar peptídeos opióides com atividades antagonistas e, quando estes são derivados da caseína, denominam-se casoxinas (MEISEL, 1998; SILVA; MALCATA, 2005).

Estes peptídeos se encontram em maiores concentrações no leite proveniente de animais com mastite e, tem como principal função fisiológica, a aceleração do trânsito intestinal. As casoxinas A, B e C são derivadas da k-caseína, enquanto a casoxina $\mathrm{D}$, proveniente da $\alpha$ s1-caseína. Destas, a casoxina $\mathrm{C}$, apresenta o maior efeito biológico dentre as demais. Porém, algumas casoxinas, quando metoxiladas durante os processos de isolamento e purificação, tornam-se potencialmente mais ativas (MEISEL; BOCKELMAN, 1999; SILVA; MALCATA, 2005).

No entanto, é importante ressaltar que no leite in natura, a atividade opioide parece prevalecer, uma vez que, a $\alpha$ e $\beta$-caseína estão em maior proporção do que a k-caseína (SCHANBACHER et al., 1998).

\section{EFEITOS NO SISTEMA GASTROINTESTI- NAL}

Durante o processo digestivo, proteínas intactas e peptídeos atingem o trato intestinal, participando da regulação de enzimas digestivas e modulação da absorção de nutrientes. Entretanto, segundo Tidona et. al. (2009), as peptidases das microvilosidades apicais podem auxiliar ou prejudicar à formação de peptídeos com atividades biológicas.

Em geral, a bioatividade de peptídeos de cadeia curta é mantida com maior facilidade, quando comparados aos de cadeia maiores. Entre- tanto, em ensaios de digestão in vitro, o grau de hidrólise de peptídeos, além de variar de acordo com o comprimento de sua cadeia, é influenciado pela natureza do peptídeo e pela presença de outros no meio (ROUFIC et al., 2006).

Entre os peptídeos que atuam no sistema gastrointestinal, destacam-se os caseinomacropeptídeos (CMP) e os caseinofosfopeptídeos (CFP). Os CMP estão relacionados com a secreção do hormônio colecistoquinina, que regula a secreção pancreática e o esvaziamento gástrico (BEUCHER et. al., 1994), enquanto o termo CFP, foi introduzido na década de 50, com o intuito de descrever peptídeos fosforilados derivados da caseína que apresentavam a propriedade de melhorar o processo de mineralização óssea de crianças portadoras de raquitismo.

Neste sentido, Mellander, em 1950, ao incubar caseína com pepsina e suco pancreático, obteve uma fração peptídica resistente à degradação posterior por outras enzimas, o que se tornou o primeiro relato de peptídeos bioativos da literatura. Este pesquisador observou que os peptídeos obtidos apresentavam elevado conteúdo de resíduos fosfoserina e aumentavam o balanço de cálcio de 39 a $78 \%$ em neonatos portadores de raquitismo. Desde então, diversas pesquisas verificaram que os CFP possuem habilidade de ligar-se a microelementos minerais, como cálcio, magnésio e ferro e, ainda a elementos-traços, como o zinco, bário, cromo, níquel, cobalto e selênio, formando complexos solúveis, o que por sua vez, facilita a absorção destes à nível intestinal (FITZGERALD, 1998; SHOLZ-AHRENS; SCHREZENMEIER, 2000).

Ainda sobre a ação das proteínas lácteas sobre o sistema gastrointestinal, Rosaneli (2002) e Rosaneli et. al. (2004) pesquisaram a ação da proteína do soro, na inibição da ação ulcerogênica do etanol absoluto, da indometacina (anti-inflamatório não-esteroidal) e de fatores de estresse (imobilização, frio e estresse químico induzido por reserpina). Estes autores constataram que os hidrolisados enzimáticos destas proteínas protegem a mucosa estomacal de ratos contra as agressões do etanol absoluto e da indometacina, inibindo as lesões ulcerativas numa faixa de $50 \%$ a $80 \%$, em relação a um controle negativo (solução salina fisiológica).

Este fato deve-se, segundo Sgarbieri (2004), a presença massiva de aminoácidos sulfurados na estrutura das proteínas do soro de leite, particularmente a cisteína, que são capazes de promover in vivo, aumento da síntese de glutationa, que é de extrema importância na proteção dos tecidos epi- 
teliais, mais precisamente na proteção da mucosa gástrica, contra vários agentes agressores.

\section{EFEITOS NO SISTEMA IMUNOLÓGICO}

Alguns peptídeos apresentam propriedades reguladoras no desenvolvimento do sistema imunológico e, em relação as suas ações, podem ser classificadas em dois grandes grupos: os imunomoduladores e os antimicrobianos.

Peptídeos derivados da proteólise enzimática das proteínas do soro modulam uma variedade de funções imunes, incluindo atividade linfocitária, secreção de citocinas, produção de anticorpos, atividade fagocitária e das células exterminadoras naturais ou células NK (do inglês Natural Killer Cell) (SAINT-SAUVEUR, 2008).

Tabela 1 - Peptídeos bioativos (PBA) derivados das proteínas do leite bovino

\begin{tabular}{|c|c|c|c|c|c|}
\hline $\begin{array}{c}\text { Grupo } \\
\text { proteico }\end{array}$ & $\begin{array}{l}\text { Proteína } \\
\text { precursora }\end{array}$ & Nome do PBA & Sequência peptídica & Fragmento de $\mathbf{A A}^{1}$ & Bioatividade \\
\hline \multirow{11}{*}{ Caseínas } & \multirow{4}{*}{ as1-caseína } & as1-casoquinina-5 & FFVAP & $\mathrm{f}(23-27)$ & Inibidor da $\mathrm{ECA}^{2}$ \\
\hline & & Caseínofosfopeptídeo & $\begin{array}{l}\text { QMEAES*IS*S*S* } \\
\text { EEIVPNS*VEQK }\end{array}$ & $\mathrm{f}(59-79)$ & $\begin{array}{l}\text { Transporte de } \\
\text { Cálcio }\end{array}$ \\
\hline & & Exorfina $\alpha$-caseína & RYLGYLE & $\mathrm{f}(90-96)$ & Agonista opioide \\
\hline & & Casoxina D & YVPFPPF & $f(-27)$ & Antagonista opioide \\
\hline & \multirow{4}{*}{$\beta$-caseína } & $\beta$-casoquinina-7 & AVPYPQR & $\mathrm{f}(177-183)$ & Inibidor da ECA \\
\hline & & Peptídeo anti-hipertensivo & KVLPVPQ & $\mathrm{f}(169-174)$ & Anti-hipertensivo \\
\hline & & Imunopeptídeo & LLY & f (191-193) & imunoestimulante \\
\hline & & $\beta$-casoquinina-10 & YQQPVLGPVR & $\mathrm{f}(23-27)$ & $\begin{array}{l}\text { Inibidor da ECA e } \\
\text { imunomodulador }\end{array}$ \\
\hline & \multirow{3}{*}{ к-caseína } & Casoplatelina & MAIPPKKNQDK & $f(106-116)$ & Antitrombótico \\
\hline & & $\begin{array}{l}\text { Peptídeo inibidor da } \\
\text { trombina }\end{array}$ & KDQDK & $f(112-116)$ & Antitrombótico \\
\hline & & Casoxina C & YIPIQYVLSR & $f(23-27)$ & Antagonista opioide \\
\hline \multirow{4}{*}{ Soroproteínas } & $\alpha$-lactoalbumina & $\alpha$-lactorfina & YGLF & $f(50-53)$ & $\begin{array}{l}\text { Agonista opioide e } \\
\text { inibidor da ECA }\end{array}$ \\
\hline & $\beta$-lactoglobulina & $\beta$-lactorfina & ALPMHIR & f $(169-174)$ & Agonista opioide \\
\hline & Soroalbumina & Serorfina & YGFQNA & f (399-404) & Agonista opioide \\
\hline & Lactoferrina & $\begin{array}{c}\text { Peptídeo inibidor da } \\
\text { trombina } \\
\text { Lactoferricina B }\end{array}$ & $\begin{array}{l}\text { FKCRRWQWRMKKL } \\
\text { GAPSITCVRRAF }\end{array}$ & $\begin{array}{l}\mathrm{f}(39-42) \\
\mathrm{f}(17-41)\end{array}$ & $\begin{array}{c}\text { Antitrombótico } \\
\text { Imunomodulador e } \\
\text { antimicrobiano }\end{array}$ \\
\hline
\end{tabular}

Adaptado de Clare \& Swaisgood (2000)

$1 \mathrm{AA}=$ aminoácidos

2ECA = enzima conversora de angiotensina 
Diversos experimentos realizados em animais, humanos e in vitro, associaram o poder imunoestimulante das proteínas do soro com a sua capacidade em estimular a síntese de glutationa, em virtude do elevado conteúdo de cisteína e de repetidas sequências glutamil-cistina na estrutura primária dessas proteínas (PACHECO et. al., 2006; SAINT-SAUVEUR, 2008). Peptídeos com a sequência glutamil-cistina seriam formados a partir da digestão de frações de albumina sérica, $\beta$-lactoglobulina e de imunoglobulina G (IgG) e, absorvidos como tal, servindo de substrato para a síntese de glutationa, que é um tripeptídeo composto de glutamato, glicina e cisteína (SGARBIERI, 2004; PACHECO et al., 2006). A glutationa encontra-se distribuída em todos os tecidos do organismo humano, produzindo diversos efeitos biológicos, como: estímulo à síntese de IGF-1 (Insulin Growth Factor 1), desenvolvimento do sistema imunológico, ação hipocolesterolêmica e antitumoral e retardo do envelhecimento em animais de laboratório (PACHECO et al., 2005; MELO, 2006).

Com a finalidade de comprovar a eficácia das proteínas isoladas do soro de leite, no sentido de melhorar a atuação do sistema imunológico, Bounous et. al. (1993) e Bounous (1998) testaram este efeito em humanos portadores da síndrome da imunodeficiência adquirida (SIDA), popularmente conhecida como HIV (Human Immunodeficiency Virus). Essa enfermidade compromete o sistema imunológico e, mesmo quando controlada por efeito de medicação, é relatado um desequilíbrio dos linfócitos TCD4+ (linfócitos de defesa do organismo) frente à prevalência dos linfócitos TCD8+ ou linfócitos de ataque (Tkiller). Embora com número reduzido de sujeitos, 3 e 4 indivíduos, respectivamente, a administração de 10 a $40 \mathrm{~g}$ diárias de proteínas do soro a estes portadores de HIV, culminou com a elevação da concentração de glutationa nos linfócitos e com aumento do número de linfócitos TCD4+, melhorando as condições gerais dos pacientes, inclusive com ganho de peso de 2 a $7 \mathrm{~kg}$, no período de 3 meses de suplementação.

Dessa maneira, fica evidenciado que o isolado da proteína do soro pode ser considerado um ótimo suplemento terapêutico para o tratamento da SIDA/HIV. A relação entre o vírus causador desta enfermidade e a glutationa é antagônica, ou seja, quando os níveis de glutationa celular são baixos, ocorre elevação da multiplicação viral, enquanto, com seu incremento há redução drástica da multiplicação do vírus. Assim, quanto mais elevada à taxa de glutationa nos linfócitos (células de defesa do sistema imunológico) dos pacientes com SIDA/ HIV, maiores serão suas chances de sobrevivência (SGARBIERE, 2004; WALZEM, 1999).

Adicionalmente, vários estudos feitos com animais mostram os efeitos anticancerígenos das proteínas do soro (PAPENBURG et. al., 1990). Em experimentos realizados com roedores, verificou-se que nos produtos lácteos o poder inibidor da proliferação de células cancerígenas está contido especificamente nestas proteínas (SGARBIERI, 2004).

Neste sentido, McIntosh et. al. (1998) e McIntosh e Le Leu (2001) estudaram a ação de várias proteínas da dieta (proteínas de soro do leite, caseína, proteínas da carne bovina e da soja) contra o desenvolvimento de tumores de cólon induzidos pelo carcinógeno 1,2-dimetilhidrazina. Nestes estudos, os autores constataram que dietas contendo as proteínas do soro de leite inibiram o aparecimento e o crescimento de tumores de cólon de forma mais eficaz que a caseína, as proteínas de carne bovina e as de soja, nesta ordem.

Além disso, outros pesquisadores constataram a capacidade inibitória das proteínas do soro de leite sobre o câncer de cabeça e pescoço (CHMIEL, 1997) e sobre culturas de células cancerígenas (BOURTOURAULT et al., 1991), inibindo seletivamente o desenvolvimento destas células. Neste sentido, em cultivos da linha MCF-7 de células de câncer de mama e linhagens de células de câncer de próstata, a adição de proteínas do soro do leite diminuiu o desenvolvimento de células cancerígenas (BOURTOURAULT et. al., 1991).

A hipótese mais aceita que explica o efeito protetor das proteínas do soro do leite frente ao câncer, está relacionada com o aumento das concentrações de glutationa nos tecidos, que atua conjuntamente com as enzimas glutationa peroxidade selênio dependente (GPx) e com as da família das glutationa transferases (GST) (SIES, 1999). Desta forma, a atividade anticancerígena está relacionada, por um lado, pela ação da GPx, nos peróxidos de hidrogênio, radicais livres e espécies reativas ao oxigênio, que podem danificar o DNA e, por outro lado, pela ação das enzimas da família das GST, que catalisam a conjugação de compostos tóxicos, incluindo mutagênicos e carcinogênicos, para eliminação do organismo (COLES; KETTERER, 1990).

Como dito anteriormente, além da existência de peptídeos com propriedades imunomoduladoras, existem aqueles com atividade antimicrobiana, que também auxiliam na regulação do sistema 
imunológico. Os peptídeos antimicrobianos são reconhecidos como importantes componentes da imunidade inata, já que são encontrados tanto nas superfícies epiteliais, como dentro de células fagocíticas granulares de mamíferos, capazes não somente de inibir microrganismos, mas também de modular respostas inflamatórias (GOBBETI et. al., 2004; HAQUE; CHAND, 2008).

A primeira descoberta sobre a presença de propriedades antimicrobianas no leite foi feita por Jones e Simms em 1930, onde através do tratamento do leite com coalho, estes pesquisadores encontraram uma substância denominada lactenina, que por sua vez possuía capacidade de inibir bactérias do gênero estreptococos (GOBBETI et. al., 2004; HAQUE; CHAND, 2008).

Um peptídeo denominado casecidina, obtidos da digestão de as2-caseína com quimosina em $\mathrm{PH}$ neutro, foram os primeiros peptídeos lácteos de defesa a serem relatados, com atividade contra bactérias gram-positivas, incluindo Staphylococcus, Sarcina spp. Bacillus subtilis, Diplococcus pneumoniae e Streptococcus pyogenes (SILVA; MALCATA, 2005; BENKERROUM, 2010). Outro peptídeo antimicrobiano, porém derivado da as1-caseína tratada com quimosina é a isracidina, o qual, in vivo, exerce uma forte ação protetora contra Staphylococcus aureus, Streptococcus pyogenes e Listeria monocytogenes (GOBBETI et. al., 2004; BENKERROUM, 2010). A isracidina também protege vacas de mastite quando injetado no interior do úbere, a níveis comparáveis aos observados em tratamentos com antibióticos padrões (LAHOV; REGELSON, 1996).

Há também relatos mostrando o efeito inibitório sobre o crescimento bacteriano, de peptídeos derivados da k-caseína, como a kapacina, que apresentam a capacidade de ligar-se a enterotoxinas e inibir adesão de vírus e bactérias, como por exemplo, a ligação de bactérias cariogênicas na superfície oral (NESSER et al., 1994).

Atividades antimicrobianas também têm sido demonstradas para as proteínas do soro do leite, como as atribuídas à lactoferrina, lactoperoxidase, $\alpha$-lactoalbumina e as imunoglobulinas.

A lactoferrina, bem como seu peptídio lactoferricina, inibem a proliferação e o crescimento de bactérias gram-positivas e gram-negativas, bem como leveduras, fungos e protozoários, por quelar (sequestrar) o ferro disponível no ambiente, enquanto que a lactoperoxidase tem propriedade bactericida através da oxidação de tiocianatos em presença de peróxido de hidrogênio (H2O2) (NABET; LINDEN, 2001). A hidrólise enzimática da lactoferrina libera peptídios com ação inibitória ao vírus da hepatite $C$ e com ação contra a bactéria Helicobacter pylori (IKEDA et al., 1998). A lactoferricina, peptídio resultante da ação da pepsina sobre a lactoferrina, apresenta além da atividade antimicrobiana (BELLAMY et al., 1992), ação apoptótica sobre células da leucemia humana (ROY et al., 2002).

\section{PEPTÍDEOS BIOATIVOS EM DERIVADOS LÁCTEOS}

Podemos observar que o leite contém diversos PBA presentes no interior da estrutura primária de suas proteínas, requerendo proteólise para sua liberação. Em alimentos lácteos, tem sido dada atenção especial aos PBA derivados de hidrolisados proteicos e produtos fermentados (KORHONEN; PIHLANTO, 2006).

Sabe-se que através da fermentação do leite pela atividade de bactérias lácticas, como no processamento do iogurte, leite fermentado e queijo, obtêm-se diversos PBA. Estes derivados, sob certas condições, podem proporcionar efeitos positivos na modulação de sistemas fisiológicos do organismo, quando ingeridos como parte da dieta diária, porém, os efeitos referentes a estes produtos tradicionais, ainda não estão bem estabelecidos. A Tabela 2 apresenta estudos que evidenciaram a ocorrência de peptídeos em algumas variedades de queijo e produtos lácteos fermentados.

Da mesma maneira, existem diversos produtos lácteos enriquecidos com PBA capazes de diminuir a pressão arterial, como fica evidenciado em estudos demonstrados na Tabela 3. Em todos estes derivados, a ação anti-hipertensiva deve-se a presença do tripeptídeos VPP (valina-prolina-prolina) e IPP (isoleucina-prolina-prolina), os quais possuem efetividade hipotensiva reconhecida em humanos, após a ingestão por um período de 2 a 7 semanas (TORRUCO-UCO et. al., 2008). 
Tabela 2 - Peptídeos bioativos identificados em variedades de queijos e produtos lácteos fermentados e suas funcionalidades

\begin{tabular}{|c|c|c|}
\hline Derivados Lácteos & Peptídeo identificado & Bioatividade \\
\hline \multicolumn{3}{|l|}{ Variedades de queijos: } \\
\hline Cheddar & Fragmentos da $\alpha$ s1- e $\beta$-caseína & Atuam como fosfopeptídeos \\
\hline $\begin{array}{l}\text { Variedades italianas: Mussarela, Crescenza, } \\
\text { Italico e Gorgonzola. }\end{array}$ & $\mathrm{f}(58-72)$ da $\beta$-caseína & Inibidores da ECA \\
\hline Gouda & $\mathrm{f}(1-9)$ da $\alpha$ s1-caseína e $\mathrm{f}(60-68)$ da $\beta$-caseína & Inibidores da ECA \\
\hline Emmental & Fragmentos da $\alpha$ s1- e $\beta$-caseína & $\begin{array}{l}\text { Imunoestimulantes atuam como } \\
\text { fosfopeptídeos, ação antimicrobiana e } \\
\text { inibitória da ECA }\end{array}$ \\
\hline \multicolumn{3}{|l|}{ Produtos lácteos fermentados: } \\
\hline Leite acidificado & $\begin{array}{l}\mathrm{f}(74-76) \text { e } \mathrm{f}(84-86) \text { da } \square \text {-caseína e } \mathrm{f}(108 \text { - } \\
111) \text { da } \square \text {-caseína }\end{array}$ & Anti-hipertensivo \\
\hline Iogurte & Sequência de aminoácidos (S-K-V-Y-P) & Inibidores da ECA \\
\hline
\end{tabular}

Tabela 3 - Estudos em humanos com derivados lácteos e peptídeos com ação hipotensora

\begin{tabular}{|c|c|c|c|c|c|c|}
\hline $\begin{array}{l}\text { Derivados } \\
\text { Lácteos }\end{array}$ & Descrição do estudo & Dose administrada & $\begin{array}{c}\text { Duração } \\
\text { Do } \\
\text { Tratamento }\end{array}$ & $\begin{array}{l}\text { Efeito sobre a } \\
\text { pressão arterial } \\
\text { sistólica }\end{array}$ & Valor de $\mathrm{P}$ & Referências \\
\hline \multirow{3}{*}{$\begin{array}{c}\text { Leite } \\
\text { fermentado }\end{array}$} & $\left|\begin{array}{c}\text { Estudo duplo-cego } \\
\text { r a n d o m i z a do e e } \\
\text { controlado com placebo } \\
\text { em } 30 \text { indivíduos com } \\
\text { hipertensão leve. }\end{array}\right|$ & $\begin{array}{c}95 \mathrm{ml} / \text { dia } \\
\text { Equivalente: } \\
1,1 \mathrm{mg} \text { de IPP } \\
+ \\
1,5 \mathrm{mg} \text { de VPP }\end{array}$ & 8 semanas & $-14,1 \mathrm{~mm} \mathrm{Hg}$ & $\mathrm{P}<0,01$ & $\begin{array}{c}\text { HATA } \\
\text { et al. (1996) }\end{array}$ \\
\hline & $\begin{array}{c}\text { Estudo randomizado e } \\
\text { controlado com placebo } \\
\text { em } 39 \text { indivíduos com } \\
\text { hipertensão leve. }\end{array} \mid$ & $\begin{array}{c}150 \mathrm{ml} / \mathrm{dia} \\
\text { Equivalente: } \\
2,25 \mathrm{mg} \text { de IPP } \\
+ \\
3,0-3,75 \mathrm{mg} \text { de VPP }\end{array}$ & 21 semanas & $-6,7 \mathrm{~mm} \mathrm{Hg}$ & $\mathrm{P}<0,05$ & $\begin{array}{c}\text { SEPPO } \\
\text { Et. al. (2003) }\end{array}$ \\
\hline & $\begin{array}{c}\text { Estudo duplo } \\
\text { cego, randomizado } \\
\text { e controlado com } \\
\text { placebo em 94 homens } \\
\text { hipertensos. }\end{array}$ & $\begin{array}{c}2 \times 150 \mathrm{~mL} / \mathrm{dia} \\
\text { Equivalente: } \\
22,5 \mathrm{mg} \text { de IPP } \\
+ \\
30 \mathrm{mg} \text { de VPP }\end{array}$ & 10 semanas & $-4,1 \mathrm{~mm} \mathrm{Hg}$ & $\mathrm{P}<0,001$ & $\begin{array}{c}\text { JAUHIAINEN } \\
\text { et. al. (2005) }\end{array}$ \\
\hline \multirow{2}{*}{$\begin{array}{l}\text { Comprimido } \\
\text { de leite } \\
\text { fermentado } \\
\text { em pó }\end{array}$} & \begin{tabular}{|c} 
Estudo duplo-cego, \\
r a n d o m i z a d o e e \\
controlado com placebo \\
em 144 indivíduos com \\
hipertensão normal alta \\
(NA) ou hipertensão leve \\
(HL).
\end{tabular} & $\begin{array}{c}200 \mathrm{~mL} / \mathrm{dia} \\
\text { Equivalente: } \\
\begin{array}{c}1,6 \mathrm{mg} \text { de IPP } \\
+\end{array} \\
1.5 \mathrm{mg} \text { de VPP }\end{array}$ & 12 semanas & $\begin{array}{l}4,6 \text { mm Hg (grupo } \\
\mathrm{NA} \text { ) } \\
9,5 \mathrm{~mm} \mathrm{Hg} \text { (grupo } \\
\mathrm{HL} \text { ) }\end{array}$ & $\begin{array}{l}\mathrm{P}<0,001 \\
\mathrm{P}<0,001\end{array}$ & $\begin{array}{c}\text { SANO } \\
\text { et. al. (2005) }\end{array}$ \\
\hline & \begin{tabular}{|} 
Estudo duplo-cego \\
r a n d o m i z a d o e e \\
controlado com placebo \\
em 80 indivíduos com \\
hipertensão normal alta \\
(NA) ou hipertensão leve \\
(HL).
\end{tabular} & $\begin{array}{c}6 \text { comp./dia } \\
\text { Equivalente: } \\
\begin{array}{c}4,7 \mathrm{mg} \text { de IPP } \\
+ \\
8.3 \mathrm{mg} \text { de VPP }\end{array}\end{array}$ & 4 semanas & \begin{tabular}{|}
$-3,2 \mathrm{~mm} \mathrm{Hg}$ (grupo \\
$\mathrm{NA}$ ) \\
$-1,2 \mathrm{~mm} \mathrm{Hg}$ (grupo \\
$\mathrm{HL}$ )
\end{tabular} & $\begin{array}{l}\mathrm{P}>0,05 \\
\mathrm{P}<0,01\end{array}$ & $\begin{array}{c}\text { AIHARA } \\
\text { et. al. (2005) }\end{array}$ \\
\hline
\end{tabular}




\section{CONCLUSÕES}

Atualmente, a maior divulgação e/ou acesso a informações sobre o papel dos alimentos na saúde, tem despertado grande interesse da população sobre os cuidados para com a alimentação mais saudável. Assim, com o aumento das exigências por parte dos consumidores e, consequentemente, pela indústria alimentícia, quanto à qualidade nutricional dos alimentos $\mathrm{e}$, o recente avanço científico e tecnológico em relação aos efeitos e produção dos PBA, têm-se excelentes perspectivas futuras para este emergente mercado de produtos lácteos funcionais, o que auxiliaria o fortalecimento da cadeia láctea nacional.

\section{REFERÊNCIAS}

AIHARA, K. et al. Effect of powdered fermented milk with Lactobacillus helveticus on subjects with high-normal blood pressure or mild hypertension. The Journal of the American College of Nutrition, v.24, n.4, p.257-265, 2005.

ALLESCHER, H.D. et al. Effect of opioid active therapeutics on the ascending reflex pathway in the rat ileum. Neuropeptides, v.34, n.3-4, p.181-186, 2000.

BELLAMY, W. et al. Identification of the bactericidal domain of lactoferrin. Biochimica et Biophysica Acta (BBA), v.1121, n.1-2, p.130-136, 1992.

BENKERROUM, N. Antimicrobial peptides generated from milk proteins: a survey and prospectus for application in the food industry. A review. International of Dairy Technology, v.63, n.3, p.320-338, 2010.

BEUCHER, S.et al. Effects of gastric digestive products from casein on CCK release by intestinal cells in rat. The Journal of Nutritional Biochemistry, v.5, n.12, p.578-584, 1994.

BODNAR, R.J. Endogenous opiates and behavior: 2008. Peptides, v.30, n.12, p.2432-2479, 2009.

BOUNOUS, G. et al. Whey protein as a food supplement in HIV-seropositive individuals. Clinical \& Investigative Medicine, v.16, n.3, p.204-209, 1993.

BOUNOUS, G.; KONGSHAVN, P.; GOLD, P. The immunoenhancing property of dietary whey protein concentrate. Clinical \& Investigative Medicine, v.11, n.14, p.271-278, 1998.

BOURTOURAULT, M. Effet des protéines du lactosérum bovin sur la multiplication de cellules cancéreuses humaines. Scholarly Societies Project, v.185, n.5, p.319-323, 1991.

CHMIEL, J.F. Anti-tumor effects of dietary whey protein and its value for head and neck cancer patients. In: International Dairy Federation: Proceedings of the 3rd International Whey Conference; 1997. Chicago. Brussels, Belgium: International Dairy Federation; 1998. p.310-314.

CLARE, D.A.; CATIGNANI, G.L.; SWAISGOOD, H.E. Biodefense properties of milk: The role of antimicrobial proteins and peptides. Current Pharmaceutical Design, v.9, n.16, p.1239-1255, 2003.

CLARE, D.A.; SWAISGOOD, H.E. Bioactive milk peptides: A prospectus. Journal of Dairy Science, v.83, n.6, p.1187-1195, 2000.

COLES, B., KETTERER, B. The role of glutathione and glutathione transferases in chemical carcinogenesis. Critical Reviews in Biochemistry and Molecular Biology, v.25, n.1, p.47-70, 1990.

FITZGERALD, R.J. Potential uses of caseinophosphopeptides. International Dairy Journal, v.8, n.5-6, p.451-457, 1998.

FOX, P.F. et al. Fundamentals of cheese science. New York: Aspen, 2000. 587p.

HAQUE, E.; CHAND, R. Antihypertensive and antimicrobial bioactive peptides from milk proteins. European Food Research and Technology, v.227, n.1, p.7-15, 2008.

HARTMANN, R.; MEISEL, H. Food-derived peptides with biological activity: from research to food applications. Current Opinion in Biotechnology, v.18, n.2, p.163-169, 2007.

HATA, Y. et al. A placebo-controlled study of the effect of sour milk on blood pressure in hypertensive subjects. The American Journal of Clinical Nutrition, v.64, n.5, p.767-771, 1996.

IKEDA, K. et al. Urocortin, a newly identified corticotropin-releasing factor-related mammalian peptide, stimulates atrial natriuretic peptide and 
brain natriuretic peptide secretions from neonatal rat cardiomyocytes. Biochemical and Biophysical Research Communications, v.250, n.2, p.298-304, 1998.

JAUHIAINEN, T. et al. Lactobacillus helveticus fermented milk reduces arterial stiffness in hypertensive subjects. International Dairy Journal, v.17, n.10, p.1209-1211, 2007.

KORHONEN, H. Milk-derived bioactive peptides: From science to applications. Journal of Functional Foods I, v.1, n.2, p.177-187, 2009.

KORHONEN, H.; PIHLANTO, A. Bioactive peptides: Production and functionality. International Dairy Journal, v.16, n.9, p.945-960, 2006.

LAHOV, E., REGELSON, W. Antibacterial and stimulating casein-derives substances from milk: casecidin, isracidin peptides. Food and Chemical Toxicology, v.34, n.1, p.131-145, 1996.

LIGNITTO, L. at al. Angiotensin-converting enzyme inhibitory activity of water-soluble extracts of Asiago d'allevo cheese. International Dairy Journal, v.20, n.1, p.11-17, 2010.

McINTOSH, G.H.; LE LEU, R.K. The influence of dietary proteins on colon cancer risk. Nutrition Research, v.21, n.7, p.1053-1066, 2001.

McINTOSH, G.H. et al. Dairy proteins protect against dimethylhydrazine-induced intestinal cancers in rats. Journal of Nutrition, v.125, n.4, p.809-816, 1995.

MEISEL, H. Overview on milk protein-derived peptides. International Dairy Journal, v.8, n.5, p. 363-373, 1998.

MEISEL, H.; BOCKELMANN, W. Bioactive peptides encrypted in milk proteins: proteolytic activation and thropho-functional properties. Antonie van Leeuwenhoek, v.76, n.1-4, p.207-215, 1999.

MELO, A. Soro do leite estimula sistema imunológico. Ciência Hoje on-line, 2006. Disponível em: http://cienciahoje.uol.com.br/controlPanel/materia/view/2929. Acesso em: 12 mar. 2013.

NABET, P.; LINDEN, G. Constituants bioactifs in leits nutrition et same. Tec\&Doc, p.169-187, 2001.

NAGAOKA, S. et al. Comparative studies on the serum cholesterol lowering action of whey protein and soybean protein in rats. Bioscience, biotechnology, and biochemistry, v.56, n.9, p.1484-1485, 1992.

NEESER, J.R. et al. In vitro modulation of oral bacterial adhesion to saliva-coated hydroxyapatite beads by milk casein derivatives. Oral Microbiology and Immunology, v.4, n.9, p.193-201, 1994.

OLIVEIRA, D.S.; TIMM, C.D. Instabilidade da caseína em leite sem acidez adquirida. Revista Portuguesa de Ciências Veterinárias, v.102, n.1, p.435-451, 2007.

PACHECO, M.T.B. et. al. Efeito de um hidrolisado de proteínas de soro de leite e de seus peptídeos na proteção de lesões ulcerativas da mucosa gástricas de ratos. Revista de Nutrição, v.19, n.1, p.47-55, 2006.

PACHECO, M.T.B. et. al. Propriedades funcionais de hidrolisados obtidos a partir de concentrados protéicos de soro de leite. Ciência e Tecnologia dos Alimentos, v.25, n.2, p.333-338, 2005.

PAPENBURG, R. Dietary Milk proteins inhibit the evelopment of dimethylhydrazine-induced malignancy. Tumour Biology, v.11, n.3, p.129-136, 1990.

PHELAN, M. et al. Potential bioactive effects of casein hydrolysates on human cultured cells. International Dairy Journal, v.19, n.5, p.279-285, 2009.

PIHLANTO-LEPPÄLA, A.; ROKKA, T.; KORHONEN, H. Angiotensin I converting enzyme inhibitory peptides derived from bovine milk proteins. International Dairy Journal, v.8, n.4, p.325-331, 1998.

PRIPP, A.H. et al. Relantionship between proteolyses and angiotensin-I-converting enzyme inhibition in different cheeses. Food Science and Technology, v.39, n.6, p.677-683, 2006.

ROSANELI, C.F. et al. Efficacy of a Whey Concentrate on the Inhibition of Stomach Ulcerative Lesions Caused by Ethanol Ingestion. Journal of Medicinal Food, v.5, n.4, p.221-228, 2002.

ROSANELI, C.F. at al. Protective Effect of Bovine Milk Whey Protein Concentrate on the Ulcerative Lesions Caused by Subcutaneous Administration of Indomethacin. Journal of Medicinal Food, v.7, n.3, p.309-314, 2004. 
ROUFIK, S.; GAUTHIER, S. F.; TURGEON, S. L. In vitro digestibility of bioactive peptides derived from bovine $\square$-lactoglobulin. International Dairy Journal, v.16, n.4, p.294-302, 2006.

ROY, M.K. et al. Peptides From the N-terminal End of Bovine Lactoferrin Induce Apoptosis in Human Leukemic (HL-60) Cells. Journal of Dairy Science, v.85, n.9, p.2065-2074, 2002.

SAINT-SAUVEUR, D. et al. Immunomodulating properties of a whey protein isolate, its enzymatic digest and peptide fractions. International Dairy Journal, v.18, n.3, p.260- 270, 2008.

SANO, J. et al. Effect of casein hydrolysate, prepared with protease derived from Aspergillus oryzae, on subjects with high-normal blood pressure or mild hypertension. Journal of Medicinal Food, v.8, n.4, p.423-430, 2005.

SCHANBACHER, F.L. et al. Milk-born bioactive peptides. International Dairy Journal, v.8, n.5-6, p.393-403, 1998.

SEPPO, L. et al. A fermented milk high in bioactive peptides has a blood pressure-lowering effect in hypertensive subjects. The American Journal of Clinical Nutrition, v.77, n. 2, p.326-330, 2003.

SGARBIERI, V. C. Propriedades fisiológicas-funcionais das proteínas do soro de leite. Revista de Nutrição, v.17, n.4, p.397-409, 2004.

SHAH, N. P. Effects of milk-derived bioactives: an overview. British Journal of Nutrition, v.84, s.1, S3-S10, 2000.

SHAHIDI, F.; ZHONG, Y. Bioactive peptides. Journal of AOAC International, v.91, n.4, p.914-931, 2008.

SILVA, S.V.; MALCATA, F.X. Caseins as source of bioactive peptides. International Dairy Journal, v.15, n.1, p.1-15, 2005.

STURNER, R.A.; CHANG, K.J. Opioid peptide content in infant formulas. Pediatric Research, v.23, p.4-10, 1988.

TIDONA, F. et al. Bioactive peptides in dairy. Italian Journal of Animal Science, v.8, n.3, p.315-340, 2008.

TORRUCO-UCO, J.G. et al. Péptidos antihipertensi- vos, uma alternativa de tratamiento de origen natural: uma revisión. Ciencia y Tecnología Alimentaria, v.6, n.2, p.158-168, 2008.

TRIGO, J.M. et al. The endogenous opioid system: a common substrate in drug addiction. Drug and Alcohol Dependence, v.108, n.3, p.183-194, 2010.

WALZEM, R.L. Propriedades benéficas à saúde das proteínas de soro e frações de soro. Produtos e bebidas nutricionais. Texas A \& M University, p. 1-8, 1999. 